\title{
Association between insomnia and cognitive performance, gray matter volume, and white matter microstructure in cognitively unimpaired adults
}

Oriol Grau-Rivera ${ }^{1,2}$, Grégory Operto ${ }^{1}$, Carles Falcón ${ }^{1,3}$, Gonzalo Sánchez-Benavides ${ }^{1,4}$, Raffaele Cacciaglia ${ }^{1}$, Anna Brugulat-Serrat ${ }^{1}$, Nina Gramunt ${ }^{1,4}$, Gemma Salvadó ${ }^{3}$, Marc Suárez-Calvet ${ }^{1,2}$, Carolina Minguillon 1,4, Álex Iranzo ${ }^{5,6}$, Juan Domingo Gispert ${ }^{1,3,7}$, José Luis Molinuevo ${ }^{1,4,7,8^{*}}$ and for the ALFA Study

\begin{abstract}
Background: Mounting evidence links poor sleep quality with a higher risk of late-life dementia. However, the structural and cognitive correlates of insomnia are still not well understood. The study aims were to characterize the cognitive performance and brain structural pattern of cognitively unimpaired adults at increased risk for Alzheimer's disease (AD) with insomnia.
\end{abstract}

Methods: This cross-sectional study included 1683 cognitively unimpaired middle/late-middle-aged adults from the ALFA (ALzheimer and FAmilies) study who underwent neuropsychological assessment, T1-weighted structural imaging $(n=366)$, and diffusion-weighted imaging ( $n=334)$. The World Health Organization's World Mental Health Survey Initiative version of the Composite International Diagnostic Interview was used to define the presence or absence of insomnia. Multivariable regression models were used to evaluate differences in cognitive performance between individuals with and without insomnia, as well as potential interactions between insomnia and the APOE genotype. Voxel-based morphometry and tractbased spatial statistics were used to assess between-group differences and potential interactions between insomnia and the APOE genotype in gray matter volume and white matter diffusion metrics.

Results: Insomnia was reported by 615 out of 1683 participants (36.5\%), including 137 out of 366 (37.4\%) with T1-weighted structural imaging available and 119 out of 334 (35.6\%) with diffusion-weighted imaging. Individuals with insomnia ( $n=$ 615) performed worse in executive function tests than non-insomniacs and displayed lower gray matter volume in left orbitofrontal and right middle temporal cortex, bilateral precuneus, posterior cingulate cortex and thalamus, higher gray matter volume in the left caudate nucleus, and widespread reduction of mean and axial diffusivity in right hemisphere white matter tracts. Insomnia interacted with the APOE genotype, with APOE-ع4 carriers displaying lower gray matter volumes when insomnia was present, but higher volumes when insomnia was not present, in several gray matter regions, including the left angular gyrus, the bilateral superior frontal gyri, the thalami, and the right hippocampus.

(Continued on next page)

\footnotetext{
* Correspondence: jlmolinuevo@barcelonabeta.org

'Barcelonaßeta Brain Research Center (BBRC), Pasqual Maragall Foundation,

Wellington 30, 08003 Barcelona, Spain

${ }^{4}$ CIBER Fragilidad y Envejecimiento Saludable (CIBERFES), Madrid, Spain

Full list of author information is available at the end of the article
}

(c) The Author(s). 2020 Open Access This article is distributed under the terms of the Creative Commons Attribution 4.0 International License (http://creativecommons.org/licenses/by/4.0/), which permits unrestricted use, distribution, and reproduction in any medium, provided you give appropriate credit to the original author(s) and the source, provide a link to the Creative Commons license, and indicate if changes were made. The Creative Commons Public Domain Dedication waiver (http://creativecommons.org/publicdomain/zero/1.0/) applies to the data made available in this article, unless otherwise stated. 
(Continued from previous page)

Conclusions: Insomnia in cognitively unimpaired adults at increased risk for AD is associated to poorer performance in some executive functions and volume changes in cortical and subcortical gray matter, including key areas involved in Alzheimer's disease, as well as decreased white matter diffusivity.

Keywords: Sleep, Insomnia, Neurocognitive disorders, Alzheimer disease, Inflammation, Neuropsychology, Magnetic resonance imaging, Voxel-based morphometry, Diffusion-weighted imaging

\section{Introduction}

Insomnia is a sleep-wake disorder characterized by difficulty initiating or maintaining sleep, along with an impairment of daytime functioning $[1,2]$ whose prevalence in the general population oscillates from 4 to $20 \%$, according to different series [3-5].

Longitudinal epidemiological studies have linked poor sleep quality with a higher risk of late-life dementia [6,7], and sleep fragmentation has been associated with a higher incidence of Alzheimer's disease (AD) [8]. Understanding how insomnia and other causes of sleep disruption generate a higher vulnerability for $\mathrm{AD}$ constitutes a focus of major interest, given the potential of sleep quality as a therapeutic target for dementia prevention.

Increasing evidence suggests that sleep deprivation promotes the accumulation of $\beta$-amyloid and tau in the brain, which may be an important mechanism linking sleep disturbances and cognitive impairment $[9,10]$. However, other mechanisms may drive this association. For instance, brain structural differences in individuals with poor sleep quality may contribute to lower the threshold for cognitive impairment [11-13]. In support of this hypothesis, previous neuroimaging studies have described lower gray matter volume involving wellknown AD-vulnerable regions, such as precuneus, hippocampus, and cingulate gyrus in patients with insomnia [12, 14-18]. In addition, two independent studies have found, respectively, that poor sleep quality is associated to a higher rate of cortical atrophy [19] and reduced volume in brain regions usually affected in mild cognitive impairment and $\mathrm{AD}$ [13] in cognitively unimpaired adults. However, these studies have not evaluated potential interactions between sleep quality and $A P O E$ genotype, although previous evidence suggests that sleep quality interacts with $A P O E$ genotype in determining the risk of $\mathrm{AD}$ and the burden of $\beta$-amyloid and tau pathology in the brain $[20,21]$.

On the other hand, diffusion tensor imaging studies have shown decreased fractional anisotropy (which denotes microstructural integrity loss) in several white matter tracts in patients with insomnia and community-dwelling individuals with self-reported poor sleep quality [11, 22, 23].

In the present study, we aimed to characterize the pattern of cognitive performance, gray matter morphometry, and white matter microstructure associated with the presence of insomnia in a cohort of middle/late-middleaged cognitively unimpaired individuals from the ALFA (ALzheimer and FAmilies) study [24]. Notably, the sample used in the present study has been enriched with AD risk factors, therefore potentiating possible associations between sleep quality and AD-related brain changes. We hypothesize that individuals with insomnia will display poorer performance in neuropsychological tests, lower brain volume involving areas usually involved in $\mathrm{AD}$ and altered white matter microstructure compared with noninsomniacs, with a more deleterious effect of insomnia being expected among $A P O E-\varepsilon 4$ carriers.

\section{Methods \\ Participants}

Participants were selected from the ALFA study cohort, which has been enriched for AD risk factors in terms of family history and $A P O E-\varepsilon 4$ genotype, and whose aim is to identify potential biomarkers and characterize early pathophysiological changes related to AD [24]. This study includes 2473 cognitively unimpaired adults (Clinical Dementia Rating $=0$ and performance in the normal range in a screening neuropsychological test battery), mostly offspring of AD patients, aged between 45 and 75, recruited from the general population. The ALFA study excludes participants with current major depression or general anxiety disorder, bipolar disorder, schizophrenia, severe auditory and/or visual disorder, neurodevelopmental and/or psychomotor disorder, history of severe renal or hepatic insufficiency, chronic pneumopathy with long-term domiciliary oxygen, solid organ transplantation, fibromyalgia, active cancer, acquired cerebral damage, uncontrolled epileptic seizures, neurodegenerative disease, multiple sclerosis, or any other medical condition that might interfere in normal cognitive performance, as well as family history consistent with autosomal dominant AD. For the present study, we additionally excluded subjects with any psychiatric condition (besides those specified in the ALFA study exclusion criteria), current use of psychotropic medication, sleep-wake disorders other than insomnia, or missing data, rendering a study sample of 1683 participants (Fig. 1). Of these, 404 underwent magnetic resonance image (MRI) and had suitable images either for morphometric analyses $(n=366)$ and/or diffusion-weighted imaging (DWI) analyses $(n=334)$ (Fig. 1$)$. The study was approved 


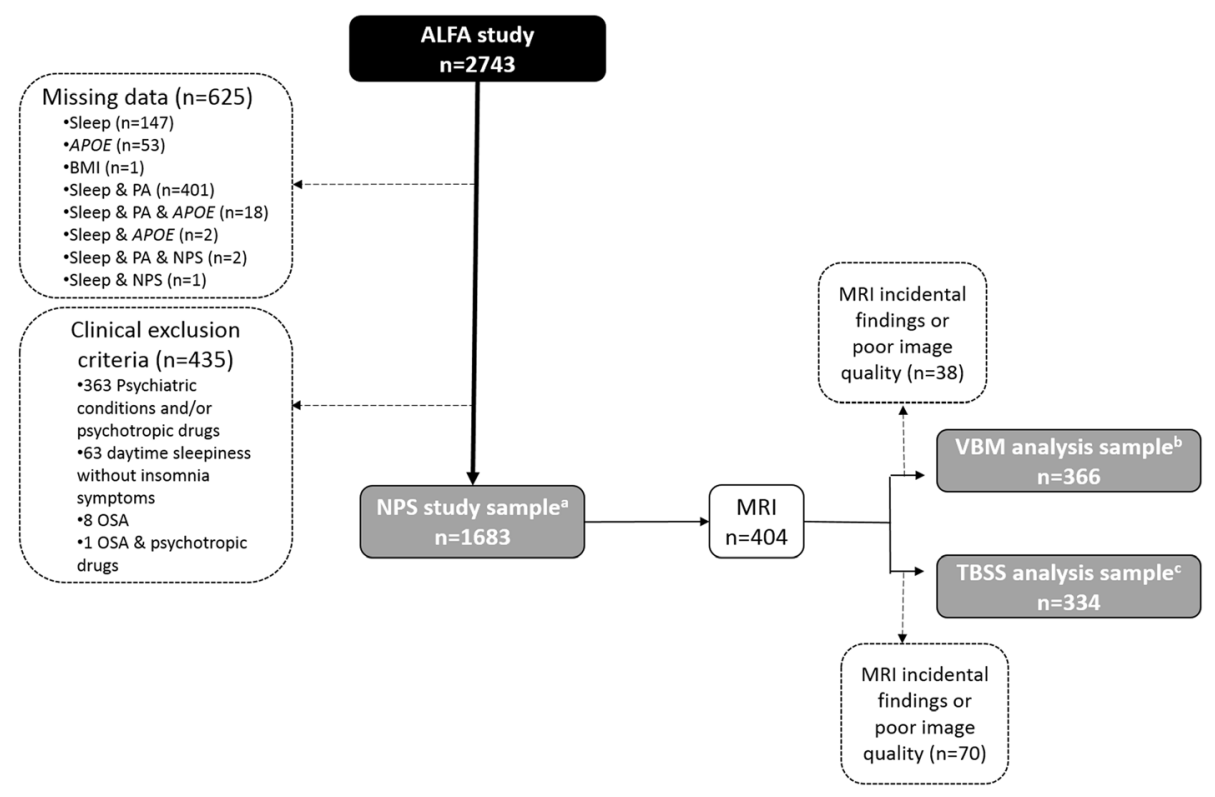

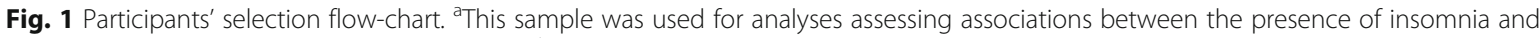

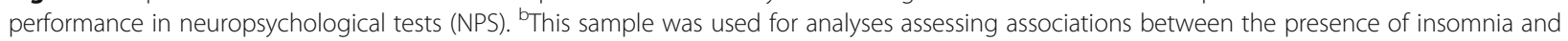
gray matter volume. ${ }^{\complement}$ This sample was used for analyses assessing associations between the presence of insomnia and white matter diffusion imaging parameters

by the Ethics Committee of the "Parc de Salut Mar" (Barcelona, Spain).

\section{Sleep assessment}

The presence of insomnia was assessed with the Spanish version of the World Mental Health Survey Initiative Version of the World Health Organization Composite International Diagnostic Interview (WMH-CIDI) $[25,26]$. The CIDI is a standardized instrument intended for use in epidemiological studies that can generate diagnoses according to the DSM-IV and ICD-10 criteria. The following questions, included in the WMH-CIDI, were asked to all participants: "Did you have a period lasting two weeks or longer in the past 12 months when you experienced any of the following: (1) Problems getting to sleep, when nearly every night it took you two hours or longer before you could fall asleep (2) Problems staying asleep, when you woke up nearly every night and took an hour or more to get back to sleep (3) Problems waking up too early, when you woke up nearly every morning at least two hours earlier than you wanted to". Insomnia was categorized as present if at least one of these questions was positively answered, or absent if all answers were negative. The self-reported number of sleep hours in a day was also registered for all participants. An additional question from the CIDI-WHM ("Did you have a period lasting two weeks or longer in the past 12 months when you experienced problems feeling sleepy during the day") was used to screen for other potentially undiagnosed sleep-wake disorders in the control group (e.g., obstructive sleep apnea), and those participants without insomnia who answered positively to this question were excluded from the study (Fig. 1).

\section{Neuropsychological and mood evaluation}

The Spanish version of the Memory Binding Test (MBT) [27] was used to evaluate episodic memory. The MBT includes four variables: immediate total paired recall (TPR), immediate total free recall (TFR), delayed total paired recall (TDPR), and delayed total free recall (TDFR), which evaluate free and cued recalls in immediate and delayed trials. Executive functions were assessed with five WAIS-IV subtests [28]: Digit Span (measure of immediate and working memory); Coding subtest (measure of processing speed and attention); Matrix Reasoning and Visual Puzzles (measures of fluid intelligence, logic and executive functioning, and visual reasoning, respectively); and Similarities (measure of abstract verbal reasoning). Anxiety and depressive symptoms were measured by summing the scores of each component of the Goldberg Anxiety and Depression Scale (GADS) [29].

\section{Image acquisition and processing}

MRI scans were performed using a 3-T General Electric Discovery scanner. High-resolution 3D structural T1weighted images were obtained using a fast spoiled gradient-echo sequence with the following parameters: Repetition time $=6.16 \mathrm{~ms}$, echo time $=2.33 \mathrm{~ms}$, inversion 
time $=450 \mathrm{~ms}$, flip angle $12^{\circ}$, matrix size $=256 \times 256 \times$ 174 , and voxel size $=1 \mathrm{~mm}^{3}$ isotropic. The DWI protocol consisted in an echo-planar imaging sequence with 64 diffusion-encoding directions $\left(b=1000 \mathrm{~s} \mathrm{~mm}^{-2}\right)$ and one T2-weighted baseline $(b=0)$, a field of view of $256 \times 256$ $\mathrm{mm}$, and an imaging matrix of $128 \times 128$ with 56 slices (thickness $=2 \mathrm{~mm}$ ) and 2-mm isotropic voxels. Gray matter segmentation was performed with SPM12 (Statistical Parametric Mapping, Welcome Trust Centre for Neuroimaging, UK; http://www.fil.ion.ucl.ac.uk/spm). T1 images were normalized to the Montreal Neurological Institute space using DARTEL and smoothed with a 6-mm fullwidth at half maximum Gaussian kernel [30]. DWI images were denoised and corrected for eddy current distortion as described elsewhere [31], then analyzed using FMRIB Software Library (FSL; http://www.fmrib.ox.ac.uk/fsl). Fractional anisotropy (FA), mean (MD), axial (AxD), and radial diffusivity $(\mathrm{RD})$ maps were obtained with DTIFit. Skeletonized maps were generated with Tract-Based Spatial Statistics (TBSS) [32]. A group mean FA image was used to generate the mean FA skeleton (binarized with FA $>0.2$ threshold). Aligned FA, MD, AxD, and RD data from each subject were projected onto this skeleton. Voxel-wise general linear model statistics were fed with the resulting data. The same workflow was applied to each parametric map. Significant clusters were anatomically labeled using the Johns Hopkins University tract-based white matter atlas [33].

\section{Statistical analyses}

Differences in demographic and clinical variables between individuals with and without insomnia, as well as differences in the prevalence of insomnia based on the $A P O E$ status ( $\varepsilon 4$ non-carrier, $\varepsilon 4$ heterozygous, or $\varepsilon 4$ homozygous), were evaluated with two-sided $t$ test or chi-squared test. We also performed a logistic regression to calculate the odds of having insomnia as a function of the $A P O E$ status while adjusting by age and sex. Potential confounders for those analyses evaluating the effect of insomnia in different outcomes were selected a priori based on well-known risk factors for sleep disturbances and/or cognitive impairment, as well as other variables associated to brain function and/or structure, such as cardiovascular risk factors [34-36], APOE $\varepsilon 4$ allele carriership [37-40], body mass index (BMI) [41-43], and the level of anxiety and depression [36, 44, 45], among others. Associations between the presence of insomnia and cognitive performance were first evaluated with a multivariable linear regression model with a $p$ value threshold for statistical significance of $p<0.005$ using a Bonferroni-type correction $(\approx 0.05$ divided by nine cognitive outcomes). Gray matter volume between-group differences were evaluated with two-sample $t$ test using voxel-based morphometry (VBM) and the general linear model method implemented in SPM12. As we expected a small effect size [14, 15], we used a liberal threshold of $p<0.005$ uncorrected for multiple comparisons and a cluster-extent threshold $(k)$ of 100 voxels and subsequently assessed whether any significant cluster survived family-wise error (FWE) correction for multiple comparisons $(p<0.05)$. For the TBSS analysis, the number of permutations was set at 5000. Statistical significance was set at $p<0.05$, after FWE correction, using the threshold-free cluster enhancement option, implemented in FSL [46]. TBSS results were processed using tbss_fill script to aid visualization. All statistical analyses were adjusted by age, sex, education, number of $A P O E-\varepsilon 4$ alleles, GADS, and BMI. VBM analyses were also adjusted by squared age (to account for non-linear effects) [38] and total intracranial volume. We did not adjust TBSS analyses for age squared, as we did not found evidence of a non-linear association between age and TBSS metrics in a previous work based on the same dataset [39]. Neither we included a quadratic term for age in cognitive performance analyses, as doing so did not substantially modify the models. We did not adjust the analyses for the presence of diabetes mellitus due to its low prevalence in our sample $(<4 \%)$ and balanced distribution among subjects with and without insomnia (Table 1).

We also evaluated potential interactions between insomnia and $A P O E$ status, in cognitive performance, white matter diffusivity, and gray matter volume. For analyses evaluating the effect of this interaction on cognitive performance, we built different models assuming different potential genetic effects. Thus, $A P O E$ status ( $\varepsilon 4$ noncarriers $/ \varepsilon 4$ heterozygous/ $\varepsilon 4$ homozygous) was included in regression models as a continuous variable and coded as $0 / 1 / 2$ in the additive model, as $0 / 1 / 1$ in the dominant model, and as $0 / 0 / 1$ in the recessive model. Significance threshold for these analyses was set at $p<0.0019(\approx 0.05$ divided by nine cognitive outcomes $x$ three genetic models). For neuroimaging analyses, we included six dummy regressors accounting for all possible combinations between $A P O E$ status and the presence or absence of insomnia, and separate $t$ tests contrast weights were specified to account for the different genetic models.

\section{Supplementary analyses}

In order to exclude other potential sources of bias, we performed a supplementary analysis controlling by additional confounders [self-reported hypertension, dyslipidemia, and level of physical activity (defined as "active" if engaged in moderate physical activity at least $150 \mathrm{~min} /$ week or vigorous physical activity at least $75 \mathrm{~min} /$ week, or "inactive" otherwise)].

\section{Results}

Six hundred fifteen participants fulfilled the criteria used for insomnia (36.5\%). Compared with non-insomniacs 
Table 1 Demographic, genetic, and clinical characteristics in the entire sample

\begin{tabular}{|c|c|c|c|c|}
\hline \multirow[b]{2}{*}{ Characteristics } & \multicolumn{4}{|c|}{ Participant group } \\
\hline & All $(n=1683)$ & Controls $(n=1068)$ & Insomnia $(n=615)$ & $p$ \\
\hline Age, mean (SD), years & $55.8(6.7)$ & $55.4(6.5)$ & $56.6(6.8)$ & $<.001$ \\
\hline Female, no. (\%) & $1018(60.5)$ & $593(55.5)$ & $425(69.1)$ & $<.001$ \\
\hline Education, mean (SD), years & $13.6(3.5)$ & $13.8(3.5)$ & $13.2(3.5)$ & .002 \\
\hline \multicolumn{5}{|l|}{ APOع4 allele status, no. (\%) } \\
\hline Non-carriers & $1108(65.8)$ & $703(65.8)$ & $405(65.9)$ & \\
\hline Heterozygotes & 515 (30.6) & $321(30.1)$ & $194(31.5)$ & .246 \\
\hline Homozygotes & $60(3.6)$ & $44(4.1)$ & $16(2.6)$ & \\
\hline BMI, mean (SD), kg/m² & $26.6(4.2)$ & $26.5(4.1)$ & $26.7(4.3)$ & .406 \\
\hline Sleep duration, hours (SD) & $7(0.8)$ & $7.2(0.8)$ & $6.7(0.9)$ & $<.001$ \\
\hline GADS (SD) & $0.6(1.4)$ & $0.5(1.1)$ & $1.0(1.7)$ & $<.001$ \\
\hline Physically active, no. (\%) & $1057(62.8)$ & $674(63.1)$ & $383(62.3)$ & .734 \\
\hline Hypertension, no. (\%) & $308(18.3)$ & $191(17.9)$ & $117(19.0)$ & .560 \\
\hline Dyslipidemia, no. (\%) & $497(29.5)$ & $300(28.1)$ & $197(32.0)$ & .088 \\
\hline Diabetes mellitus, no. (\%) & $59(3.5)$ & $40(3.8)$ & $19(3.1)$ & .481 \\
\hline
\end{tabular}

$B M I$ body mass index, GADS Sum of Goldberg Anxiety and Depression Scale scores

(controls), these participants were older, reported less years of education and shorter sleep duration, scored higher in GADS, and included a higher percentage of women (Table 1).

In turn, insomnia was more frequent in women $(41.8 \%)$ than men (28.6\%). Among individuals with insomnia, $25.3 \%$ reported only difficulties maintaining sleep, $19.4 \%$ reported only early morning awakening, 9.6\% reported only difficulties initiating sleep, and $45.7 \%$ reported more than one insomnia symptom (21.5\% difficulties maintaining sleep and early morning awakening, 15\% difficulties initiating and maintaining sleep and early morning awakening, and 9.2\% difficulties initiating and maintaining sleep). APOE- 44 homozygotes had a lower prevalence of insomnia (26.7\%), compared with heterozygotes (37.7\%) and non-carriers (36.6\%), although this difference was not statistically significant and could be explained by the homozygous younger mean age. An age- and sex-adjusted logistic regression did not show any significant association between $A P O E-\varepsilon 4$ status and the odds of having insomnia. These characteristics were very similar in the subsample with MRI, except for an overall higher percentage of $A P O E-\varepsilon 4$ allele carriers (which was balanced among individuals with and without insomnia) due to the ALFA study recruitment strategy (Table 2).

\section{Cognitive performance analyses}

Multivariable linear regression analyses showed a significant negative association between the presence of insomnia and performance in WAIS-IV Digit Span. A negative association was also observed with WAIS-IV Coding, but this association did not survive multiple comparisons correction (Table 3). Results did not significantly change after including hypertension, dyslipidemia, and physical activity as additional covariates in the model (Table 3).

We found a trend for interactions between $A P O E-\varepsilon 4$ status and insomnia in WAIS-IV Matrix Reasoning test $(p=0.042$ in the additive model), in WAIS-IV Digit Span test $(p=0.036$ in the dominant model), and in MBT-TDFR ( $p=0.034$ in the recessive model), but none of them survived correction for multiple comparisons. When performing stratified analyses by $A P O E-\varepsilon 4$ to test the association between insomnia and cognitive performance in those domains where a trend for an interaction was found, we found a detrimental effect of insomnia on MBT-TDFR performance $(p=0.036)$ exclusively in $A P O E-\varepsilon 4$ homozygous, and a detrimental effect of insomnia only in $A P O E$ - $\varepsilon 4$ non-carriers on WAIS-IV Digit Span performance $(p<0.001)$ (Additional file 1: Figure S1). No significant associations between insomnia and WAIS-IV Matrix Reasoning test performance showed up in any of the APOE groups.

\section{VBM analysis}

Participants with insomnia displayed significantly lower volume in the left orbitofrontal cortex, bilateral posterior cingulate cortex, bilateral precuneus, bilateral middle cingulum, right middle temporal gyrus, and bilateral thalamus, as well as higher volume in the left caudate nucleus (Fig. 2, Table 4).

None of these clusters survived FWE multiple comparison correction. Results were similar after adding hypertension, dyslipidemia, and physical activity as additional covariates to 
Table 2 Demographic, genetic, and clinical data in the MRI subsample

\begin{tabular}{|c|c|c|c|c|c|c|}
\hline & \multicolumn{3}{|c|}{ Gray matter volume (VBM) analyses $(n=366)$} & \multicolumn{3}{|c|}{ White matter DWI (TBSS) analyses $(n=334)$} \\
\hline & Controls & Insomnia & $p$ & Controls & Insomnia & $p$ \\
\hline Sample size, no. (\%) & 229 & 137 & - & 215 & 119 & - \\
\hline Age, years (SD) & $56.7(7.4)$ & $56.7(7.0)$ & .917 & $56.8(7.6)$ & $56.8(6.9)$ & .962 \\
\hline Female, no. (\%) & $117(51.1)$ & $87(63.5)$ & .021 & $111(51.6)$ & $76(63.6)$ & .036 \\
\hline Education, years (SD) & $13.9(3.6)$ & $13.7(3.6)$ & .567 & $13.9(3.6)$ & $13.7(3.6)$ & .648 \\
\hline \multicolumn{7}{|l|}{ APOE-£4 allele status, no. (\%) } \\
\hline Non-carriers & $118(51.5)$ & $69(50.4)$ & .391 & $108(50.2)$ & $62(51.7)$ & .108 \\
\hline Heterozygotes & $78(34.1)$ & $54(39.4)$ & & $74(34.4)$ & $48(40.7)$ & \\
\hline Homozygotes & $33(14.4)$ & $14(10.2)$ & & $33(15.4)$ & $10(7.6)$ & \\
\hline BMI, mean (SD), kg/m2 & $26.9(4.3)$ & $26.5(3.8)$ & .353 & $26.8(4.3)$ & $26.5(3.8)$ & .639 \\
\hline GADS (SD) & $0.4(0.98)$ & $0.96(1.7)$ & $<.001$ & $0.41(1.0)$ & $1.0(1.7)$ & $<.001$ \\
\hline Hypertension, no. (\%) & $51(22.3)$ & $27(19.7)$ & .562 & $44(20.5)$ & $23(19.5)$ & .832 \\
\hline Dyslipidemia, no. (\%) & $64(28.0)$ & $42(30.1)$ & .580 & $58(27.0)$ & $38(32.2)$ & .314 \\
\hline Diabetes mellitus, no. (\%) & $7(3.1)$ & $3(2.2)$ & .622 & $6(2.8)$ & $3(2.5)$ & 0.894 \\
\hline Physically active, no. (\%) & $141(61.6)$ & $95(69.3)$ & .133 & $130(60.5)$ & $82(69.5)$ & .101 \\
\hline Sleep duration, hours (SD) & $7.2(0.70)$ & $6.7(0.93)$ & $<.001$ & $7.2(0.7)$ & $6.7(0.9)$ & $<.001$ \\
\hline Total intracranial volume (SD) & $1520.4(139.5)$ & $1471.3(156.7)$ & .002 & $1517.8(136.5)$ & $1474.0(158.2)$ & 0.009 \\
\hline
\end{tabular}

$B M I$ body mass index, GADS Sum of Goldberg Anxiety and Depression Scale scores

Table 3 Effect of insomnia on cognitive performance

\begin{tabular}{|c|c|c|c|}
\hline & $\beta$ coefficient (95\% confidence interval) & $p$ & Adjusted $R^{2}$ \\
\hline \multicolumn{4}{|l|}{ Model 1} \\
\hline MBT-TFR & $-0.24(-0.72,0.23)$ & .316 & 0.122 \\
\hline MBT-TPR & $0.04(-0.38,0.46)$ & .850 & 0.085 \\
\hline MBT-TDFR & $-0.24(-0.72,0.25)$ & .332 & 0.131 \\
\hline MBT-TDPR & $-0.08(-0.52,0.35)$ & .713 & 0.096 \\
\hline WAIS-IV Coding & $-1.28(-2.54,-0.02)$ & .046 & 0.281 \\
\hline WAIS-IV Visual Puzzles & $-0.21(-0.61,0.18)$ & .290 & 0.201 \\
\hline WAIS-IV Digit Span & $-0.75(-1.26,-0.24)$ & .004 & 0.140 \\
\hline WAIS-IV Matrix Reasoning & $-0.17(-0.55,0.22)$ & .398 & 0.234 \\
\hline WAIS-IV Similarities & $0.31(-0.11,0.73)$ & .145 & 0.220 \\
\hline \multicolumn{4}{|l|}{ Model 2} \\
\hline MBT-TFR & $-0.24(-0.71,0.23)$ & .320 & 0.121 \\
\hline MBT-TPR & $-0.04(-0.38,0.46)$ & .852 & 0.084 \\
\hline MBT-TDFR & $-0.24(-0.72,0.25)$ & .337 & 0.131 \\
\hline MBT-TDPR & $-0.08(-0.52,0.35)$ & .710 & 0.096 \\
\hline WAIS-IV Coding & $-1.28(-2.54,-0.02)$ & .046 & 0.281 \\
\hline WAIS-IV Visual Puzzles & $-0.21(-0.60,0.18)$ & .297 & 0.201 \\
\hline WAIS-IV Digit Span & $-0.75(-1.25,-0.24)$ & .004 & 0.139 \\
\hline WAIS-IV Matrix Reasoning & $-0.17(-0.55,0.22)$ & .395 & 0.233 \\
\hline WAIS-IV Similarities & $0.31(-0.11,0.73)$ & .144 & 0.223 \\
\hline
\end{tabular}




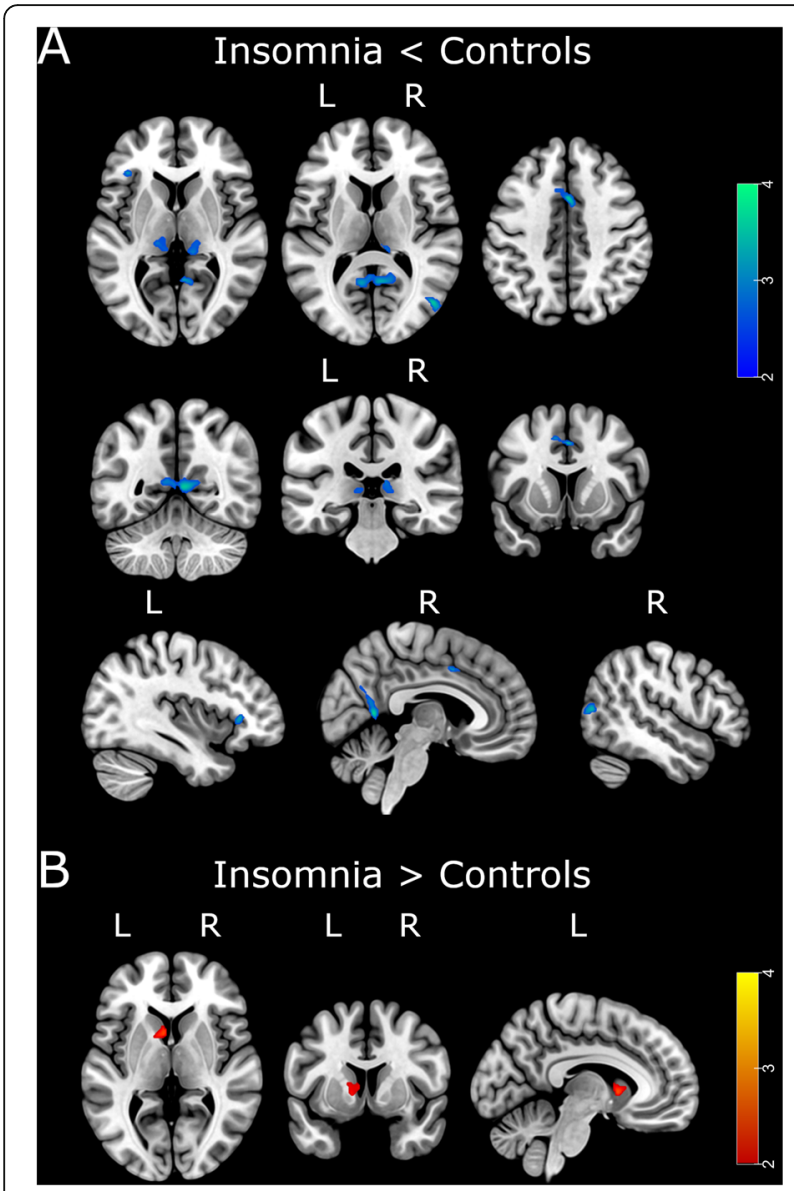

Fig. 2 Effect of insomnia on gray matter volume. a Blue-green colored regions show areas with significantly lower volume in participants with insomnia compared with controls ( $p_{\text {uncorrected }}<$ 0.005; $k=100$ ). b Red-yellow colored areas show areas with significantly higher brain volume in participants with insomnia compared with controls. L, left hemisphere; R, right hemisphere

the model (Additional file 1: Figure S2, Table S1). However, we observed an overall modest size decrease in most significant clusters, with some of them not surviving the $k=100$ threshold [left thalamus $(k=95)$ and left orbitofrontal cortex $(k=88)]$.

VBM analyses returned a significant interaction between insomnia and $A P O E$ - $\varepsilon 4$ status in several gray matter regions including the left angular, left middle temporal, bilateral superior frontal, left fusiform, and bilateral postcentral gyri, as well as the thalami and the right hippocampus (Fig. 3, Additional file 1: Table S2). In these regions, divergent structural patterns were observed among individuals with different $A P O E-\varepsilon 4$ status depending on the presence or absence of insomnia (Fig. 3). Thus, homozygous showed lower or higher gray matter volumes depending on the presence or absence of insomnia, respectively. A similar divergent structural pattern was observed in some significant clusters among heterozygous individuals, but the effect size was milder and it was not consistently observed in all brain regions. On the other hand, insomniac and non-insomnia non-carriers tended to show similar gray matter volumes in those regions where significant interactions were observed (Fig. 3).

\section{TBSS analysis}

Insomnia was associated to significantly lower MD values in white matter from the right hemisphere, involving tracts from corona radiata (anterior, superior, and posterior), internal capsule (anterior and posterior limbs and retrolenticular part), external capsule, superior and inferior longitudinal fasciculus, superior and inferior fronto-occipital fasciculus, corpus callosum, posterior thalamic radiation, fornix/stria terminalis, and cerebral peduncle (Fig. 4). In most of these regions, AxD was also reduced in subjects with insomnia. We also found a trend for reduced RD (FWE corrected $p$ value between 0.05 and 0.1 ) overlapping with those WM tracts with decreased $\mathrm{MD}$ and $\mathrm{AxD}$. We did not find any significant increase in $\mathrm{MD}, \mathrm{AxD}$, or RD in participants with insomnia, or any significant between-group difference in FA values. Additional adjustment for hypertension, dyslipidemia, and physical activity did not modify these results (Additional file 1: Figure S3).

We did not find any significant interaction between $A P O E-\varepsilon 4$ status and insomnia in white matter diffusion metrics.

\section{Discussion}

In the present study involving cognitively unimpaired individuals at increased risk for $\mathrm{AD}$, we found that insomnia was associated to poorer performance in some executive functions and to a distinctive brain macroand microstructural pattern, characterized by cortical and subcortical GMv differences and decreased white matter diffusivity. In addition, we found that the association between insomnia and gray matter volume is modulated by the $A P O E-\varepsilon 4$ status, so that $A P O E-\varepsilon 4$ carriers tend to display lower gray matter volumes in the presence of insomnia, but higher volumes when insomnia is not present.

The demographic and clinical profile of participants with insomnia from this study is similar to that reported in individuals with poor sleep quality from populationbased studies $[47,48]$. However, by using a study sample enriched for AD risk factors, we have been able to detect neuroimaging findings that differ from those reported in previous studies, particularly those showing decreased mean and axial diffusivity in white matter tracts, which may be relevant for understanding the association between poor sleep quality and AD in individuals at higher risk for this disease. 
Table $4 \mathrm{VBM}$ results of the main effect of insomnia ( $p_{\text {uncorrected }}<0.005 ; k=100$ )

\begin{tabular}{|c|c|c|c|c|c|c|c|}
\hline \multirow[b]{2}{*}{ Contrast } & \multirow[b]{2}{*}{ Anatomical area } & \multirow{2}{*}{$\begin{array}{l}\text { Cluster } \\
\text { size }(k)\end{array}$} & \multirow{2}{*}{$\begin{array}{l}\text { Peak- } \\
\text { level } \\
t \\
\text { value }\end{array}$} & \multirow[b]{2}{*}{$P_{\text {uncorrected }}$} & \multicolumn{3}{|c|}{ MNI coordinates } \\
\hline & & & & & $x$ & $y$ & $z$ \\
\hline \multirow[t]{6}{*}{$\mathrm{I}<\mathrm{C}$} & Bilateral PCC/precuneus & 557 & 3.78 & $<.001$ & 6 & -56 & 7.5 \\
\hline & Bilateral middle cingulum & 176 & 3.64 & $<.001$ & 2 & 9 & 42 \\
\hline & Right middle temporal & 156 & 3.60 & $<.001$ & 48 & -72 & 11 \\
\hline & Right thalamus & 154 & 2.97 & .002 & 12 & -33 & 5 \\
\hline & Left thalamus & 114 & 2.97 & .002 & -15 & -26 & 3 \\
\hline & Left orbitofrontal & 103 & 3.43 & $<.001$ & -41 & 29 & 3 \\
\hline$I>C$ & Left caudate & 181 & 3.02 & .001 & -6 & 9 & 3 \\
\hline
\end{tabular}

I insomnia, C controls, $P C C$ posterior cingulate cortex

Several studies have analyzed the cognitive correlate of insomnia or poor sleep quality, leading in some cases to inconsistent results [47-50]. Our findings are in line with a meta-analysis of 24 studies showing worse performance in executive functions among individuals with insomnia [50]. Subsequent studies have also reported altered executive functions in patients with insomnia $[51,52]$ and community-dwelling individuals with self-reported poor sleep quality [53]. We did not find differences in episodic memory performance, despite previous evidence of poorer memory performance among individuals with insomnia [50]. This could be explained by a selection bias towards patients with more severe insomnia (possibly linked to worse cognitive performance) in studies conducted at Sleep Units. Also, we cannot exclude an effect of insomnia on other cognitive domains, such as language and visuoperceptual or visuospatial abilities, as they were not evaluated in our study. Regarding the relationship between cognitive and neuroimaging findings, our group previously described a positive correlation between speed processing and thalamic, as well as superior longitudinal fasciculus (SLF) volume in cognitively unimpaired adults, which is consistent with our results showing a trend towards lower processing speed, as well as lower thalamic volume and altered diffusivity in the SLF in insomniacs [54].

Regarding the interaction analyses in cognitive performance, although our findings did not survive correction for multiple comparisons, the potential interaction between $A P O E$ and insomnia in delayed episodic memory performance deserves further study, as it is consistent with our finding of lower hippocampal volume in $A P O E-\varepsilon 4$ carriers with insomnia (as opposed to noninsomniac $A P O E-\varepsilon 4$ carriers), considering the pivotal role of the hippocampus in episodic memory formation [55], and it is also in line with previous evidence of a negative interaction between $A P O E-\varepsilon 4$ and sleep disturbance on memory performance [56].
Our findings of lower gray matter volume in orbitofrontal and parietal cortex, as well as middle cingulate gyrus, recapitulate some of the main brain volume differences previously reported in patients with insomnia $[14,15,17,18,57,58]$, which supports the existence of a brain structural signature associated to this condition. Regarding possible mechanistic links between these alterations and poor sleep quality, it has been hypothesized that orbitofrontal cortex abnormalities may predispose to insomnia due to altered sensing of the optimal temperature for sleep $[14,59,60]$. As far as we are concerned, lower thalamic volume has not been previously reported in patients with insomnia, although it has been associated with increased sleep fragmentation variability in cognitively unimpaired elderly subjects [61]. Thalamic involvement in sleep disturbances is biologically plausible, since regulation of wakefulness and sleep cycles largely relies on a neural network involving neurons in the brainstem, hypothalamus and basal forebrain that provides excitatory input to the thalami and cortical regions [62]. Also, degeneration of this nucleus in familial and sporadic fatal insomnia, a rare subtype of prion diseases, leads to prominent sleep disturbances [63].

Our finding of lower gray matter volume in precuneus and posterior cingulate cortex in individuals with insomnia could be linked to the higher vulnerability for cognitive impairment that has been observed in association with poor sleep quality, as these regions are early involved in $\mathrm{AD}$ [64]. Considering that poor sleep quality has been associated with higher levels of $\beta$-amyloid deposition in the brain [65-67], changes in these regions (i.e., precuneus and posterior cingulate cortex) could be related to a higher prevalence of individuals with preclinical $\mathrm{AD}$ in the insomnia group. An alternative hypothesis is that structural differences observed in individuals with insomnia may represent pre-existing morphological traits that could confer a higher vulnerability to both insomnia and cognitive impairment. 


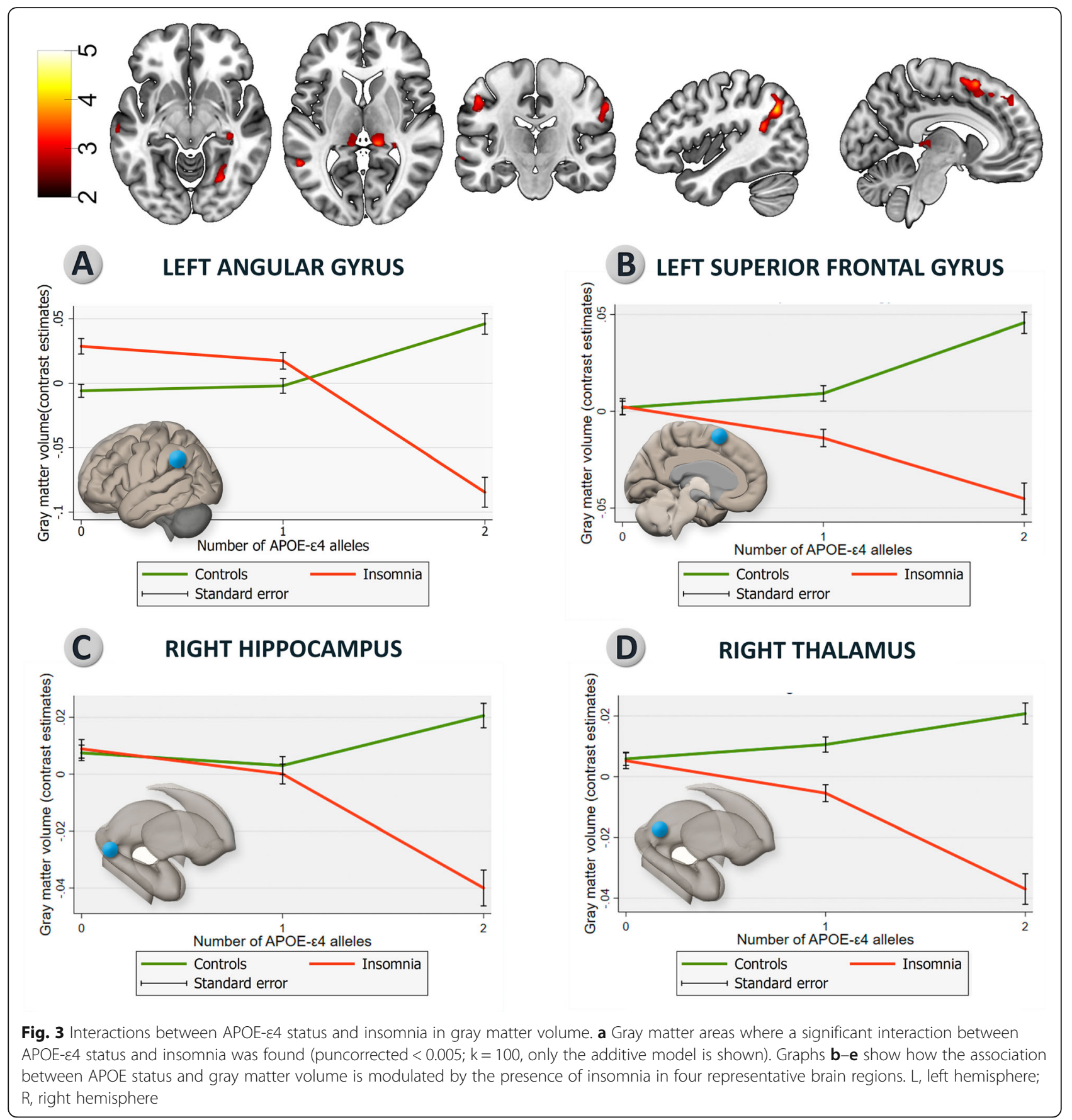

Unexpectedly, we found a greater volume in the left caudate in individuals with insomnia. The interpretation of this finding should be considered with caution, as higher caudate volume has not been previously reported in individuals with insomnia. Even so, with these limitations in mind, one potential explanation would be the existence of a higher prevalence of individuals with preclinical $\mathrm{AD}$ among those with insomnia, based on previous evidence of increased caudate size in presymptomatic PSEN1 mutation carriers, which is a genetic cause of $\mathrm{AD}$ [68], and previous findings suggest a transient size increase in some brain structures during early stages of $\mathrm{AD}[69,70]$.

Our interaction analyses point to $A P O E$ as a potential modulator in the association between sleep and brain structure, with a higher detrimental effect of insomnia on brain structure being observed among $A P O E-\varepsilon 4$ carriers. This is in line with previous evidence suggesting that $A P O E-\varepsilon 4$ carriers may be more vulnerable to different environmental factors, such as lifestyle and vascular 


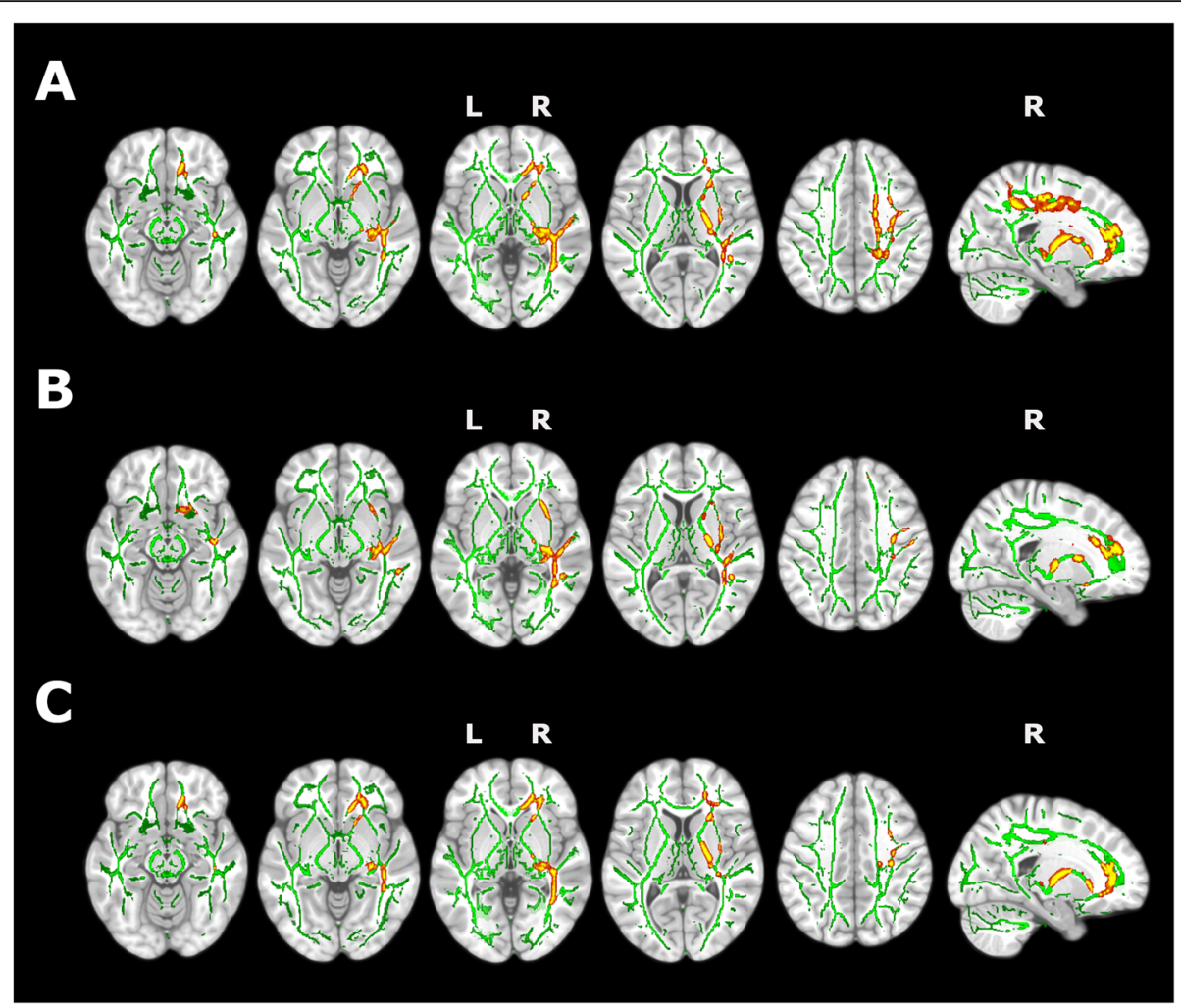

Fig. 4 Effect of insomnia on white matter microstructure. Significant white matter clusters derived from tract-based spatial statistics are represented in red-yellow over the skeletonized white matter tracts (green). Individuals with insomnia showed significantly reduced values of mean (a) and axial (b) diffusivity (FWE corrected $p$ value $<0.05$ ), and a trend for radial diffusivity (c) (FWE corrected $p$ value between 0.05 and 0.1 ), compared with normal sleepers. L, left hemisphere; R, right hemisphere

risk factors [71], and also with a previous study showing that better sleep quality attenuates the effect of $A P O E-\varepsilon 4$ on $\mathrm{AD}$ incidence and neurofibrillary tangle burden [20].

On the other hand, we also found that $A P O E-\varepsilon 4$ carriers without insomnia tend to display higher gray matter volumes compared with non-carriers, which was not expected. Assuming the hypothesis that sleep quality is gradually deteriorated as AD pathology accumulates in the brain [72], a potential explanation for this finding would be that the presence of insomnia among $A P O E-\varepsilon 4$ carriers (which are more likely to harbor AD neuropathological change than non-carriers) may be associated with a more advanced stage in the preclinical phase, whereas $A P O E-\varepsilon 4$ carriers without insomnia may include a higher proportion of individuals in an earlier AD preclinical stage, where neuroinflammation may still overcome neurodegeneration [70], resulting in overall greater gray matter volumes in this group.

We found lower diffusivity values involving widespread white matter tracts, exclusively in the right hemisphere. Previous studies have shown a right predominant loss of white matter integrity in patients with insomnia $[11,22]$. Studies in human healthy volunteers have reported an asymmetry in brain hemisphere activity during wakefulness (with left-hemisphere predominance) that is reversed during sleep [73, 74]. Whether differences in the laterality pattern across the sleep-wake cycle may be related to a higher vulnerability of the right hemisphere white matter tracts to insomnia-related disruption deserves further investigation. On the other hand, a critical difference between our findings and those reported in previous studies is that we found decreased, rather than increased diffusivity associated with insomnia [11, 23]. Acute ischemic lesions, tumoral lesions, and inflammation are among the main established causes of MD reduction in the brain tissue [75]. These three scenarios have in common a reduction in water molecules diffusivity due to their confinement to the intracellular compartment, either due to cellular swelling or cellular proliferation. Thus, one potential explanation for our findings is the existence of insomnia-related neuroinflammation involving white matter. In support of this hypothesis, a recent meta-analysis reported an association between insomnia and elevated systemic inflammatory markers [76], and murine model studies have shown that circadian clock disruption induces astrogliosis [77] and sleep disturbance is associated with higher expression of pro-inflammatory interleukins and 
microglial activation in mouse brains [78, 79]. An alternative explanation is that our results could have been driven by a hypothetical higher prevalence of preclinical AD among individuals with insomnia, as decreased MD in white matter has been previously associated with early $\beta$-amyloid deposition [80]. This could also explain the difference between our findings and those from previous studies, as our sample has been enriched for $\mathrm{AD}$ risk factors, therefore facilitating the detection of AD-related changes.

The main strengths of our study are the large size and characteristics of the study sample and its multimodal approach. Although using a sample enriched for AD risk factors may preclude the generalizability of our results, it is better suited to detect brain structural differences that might be driven by AD pathology. On the other hand, an important limitation of the present study is that we have used a subjective measure that queries for the core criteria of insomnia but does not provide more detailed information on sleep quality. In this sense, having used more specific subjective or objective sleep measures may have resulted in more robust statistical associations between sleep quality and neuroimaging and cognitive outcomes. The fact that gray matter volume differences did not survive correction for multiple comparisons (which is inherent to the small effect size of poor sleep quality on gray matter volume) and the lack of AD biomarkers are other relevant limitations in order to interpret our findings. However, we plan to address some of these questions in a further study including data from a longitudinal cohort nested in the ALFA study that incorporates CSF and PET biomarkers.

\section{Conclusions}

In summary, we confirmed that insomnia is associated to a distinctive cognitive and brain structural pattern in cognitively unimpaired individuals at risk for AD. Importantly, our findings in white matter microstructure suggest that some brain structural differences associated to poor sleep quality may be mediated by neuroinflammation. Further studies should explore whether insomnia-related brain structural differences correspond to pre-existing traits conferring higher vulnerability for either insomnia and neurodegenerative diseases, or are related to primary sleep-deprivation effects and/or AD-related effects triggered by sleep disturbances.

\section{Supplementary information}

Supplementary information accompanies this paper at https://doi.org/10. 1186/s13195-019-0547-3.

Additional file 1: Figure S1. Interaction between $A P O E$ status and insomnia in cognitive performance. Figure S2. Effect of insomnia on gray matter volume (additionally adjusted by hypertension, dyslipidemia and physical activity). Figure S3. Effect of insomnia on white matter microstructure (additionally adjusted by hypertension, dyslipidemia and physical activity). Table S1. VBM results of the main effect of insomnia, additionally adjusted by hypertension, dyslipidemia and physical activity (puncorrected $<0.005 ; \mathrm{k}=100$ ). Table S2. VBM results of interaction between insomnia and APOE genotype (puncorrected $<0.005 ; \mathrm{k}=100$ ).

\section{Abbreviations}

AD: Alzheimer's disease; ALFA: ALzheimer and Families; AxD: Axial diffusivity; BMI: Body mass index; DWI: Diffusion-weighted imaging; FA: Fractional anisotropy; GADS: Goldberg Anxiety and Depression Scale; MBT: Memory Binding Test; MD: Mean diffusivity; MRI: Magnetic resonance imaging; NPS: Neuropsychological tests; OSA: Obstructive sleep apnea; PA: Physical activity; RD: Radial diffusivity; TBSS: Tract-based spatial statistics; TDFR: Delayed total free recall; TDPR: Delayed total paired recall; TFR: Immediate total free recall; TPR: Immediate total paired recall; VBM: Voxel-based morphometry; WMH-CIDI: World Health Organization Composite International Diagnostic Interview

\section{Acknowledgements}

This publication is part of the ALFAstudy (ALzheimer and FAmilies). The authors would like to express their most sincere gratitude to the ALFA project participants, without whom this research would have not been possible. The authors would like to express recognition and heartfelt gratitude to Mrs. Blanca Brillas for her outstanding and continued support to the Pasqual Maragall Foundation to make possible a Future without Alzheimer's.

Collaborators of the ALFA study are: Jordi Camí, Marta Crous-Bou, Carme Deulofeu, Ruth Dominguez, Xavi Gotsens, Laura Hernández, Gema Huesa, Jose María González de Echavarri, Jordi Huguet, María León, Paula Marne, Eider Martínez de Arenaza, Tania Menchón, Marta Milà, Maria Pascual, Albina Polo, Sandra Pradas, Aleix Sala-Vila, Sabrina Segundo, Mahnaz Shekari, Anna Soteras, Laia Tenas, Marc Vilanova, Natàlia Vilor-Tejedor.

\section{Authors' contributions}

All authors listed (OG-R, GO, CF, GS-B, RC, AB-S, NG, GS, MS-C, CM, Al, JDG, and JLM) have made substantial contributions to the conception and design, or acquisition of data, or analysis and interpretation of data. All authors have been involved in the drafting and critical revision of the manuscript and have approved its final version. Authors have agreed to be accountable for all aspects of the work presented here.

\section{Authors' information}

Not applicable.

\section{Funding}

The research leading to these results has received funding from "la Caixa" Foundation (LCF/PR/GN17/10300004). OG-R is supported by the Spanish Ministry of Science, Innovation and Universities (FJCl-2017-33437). MS-C receives funding from the European Union's Horizon 2020 Research and Innovation Program under the Marie Sklodowska-Curie action grant agreement No 752310. CM was supported by the Spanish Ministry of Economy and Competitiveness (grant no. IEDI-2016-00690). Juan D. Gispert holds a "Ramón y Cajal" fellowship (RYC-2013-13054).

\section{Availability of data and materials}

The datasets used and/or analyzed during the current study are available from the corresponding author on reasonable request.

\section{Ethics approval and consent to participate}

The study was approved by the local ethics committee, and all individuals gave written informed consent to participate.

Consent for publication

Not applicable.

Competing interests

The authors declare that they have no competing interests. 


\section{Author details}

'Barcelonaßeta Brain Research Center (BBRC), Pasqual Maragall Foundation, Wellington 30, 08003 Barcelona, Spain. ${ }^{2}$ Servei de Neurologia, Hospital del Mar, Barcelona, Spain. ${ }^{3}$ Centro de Investigación Biomédica en Red de Bioingeniería, Biomateriales y Nanomedicina (CIBER-BBN), Madrid, Spain ${ }^{4}$ CIBER Fragilidad y Envejecimiento Saludable (CIBERFES), Madrid, Spain. ${ }^{5}$ Neurology Service, Hospital Clínic de Barcelona and Institut D'Investigacions Biomèdiques August Pi i Sunyer, Barcelona, Spain. ${ }^{6}$ Centro de Investigación Biomédica en Red sobre Enfermedades Neurodegenerativas (CIBERNED), Hospital Clínic de Barcelona, Barcelona, Spain. ${ }^{7}$ Universitat Pompeu Fabra, Barcelona, Spain. ${ }^{8} \mathrm{IMIM}$ (Hospital del Mar Medical Research Institute), Barcelona, Spain

Received: 30 July 2019 Accepted: 17 October 2019

Published online: 07 January 2020

\section{References}

1. American Academy of Sleep Medicine. International classification of sleep disorders, 3rd ed. Darien: American Academy of Sleep Medicine; 2014

2. American Psychiatric Association. Diagnostic and Statistical Manual of Mental Disorders. 2013. doi:https://doi.org/10.1176/appi.books. 9780890425596.744053.

3. Morin CM, LeBlanc M, Bélanger L, Ivers H, Mérette C, Savard J. Prevalence of insomnia and its treatment in Canada. Can J Psychiatr. 2011;56:540-8. https://doi.org/10.1177/070674371105600905.

4. Roth T, Coulouvrat C, Hajak G, Lakoma MD, Sampson NA, Shahly V, et al. Prevalence and perceived health associated with insomnia based on \{DSMIV-TR\}; \{ICD-10\}; and \{ICSD-2\} criteria: results from the America insomnia survey. Biol Psychiatry. 2011;69:592-600.

5. Ohayon MM. Epidemiological overview of sleep disorders in the general population. Sleep Med Res. 2011;2:1-9. https://doi.org/10.17241/smr. 2011.2.1.1.

6. Potvin $\mathrm{O}$, Lorrain D, Forget $H$, Dubé $M$, Grenier S, Préville $M$, et al. Sleep quality and 1-year incident cognitive impairment in communitydwelling older adults. Sleep. 2012;35:491-9. https://doi.org/10.5665/sleep. 1732.

7. Sindi S, Kåreholt I, Johansson L, Skoog J, Sjöberg L, Wang H-X, et al. Sleep disturbances and dementia risk: a multicenter study. Alzheimers Dement. 2018:1-8. https://doi.org/10.1016/j.jalz.2018.05.012.

8. Lim ASP, Kowgier M, Yu L, Buchman AS, Bennett DA. Sleep fragmentation and the risk of incident Alzheimer's disease and cognitive decline in older persons. Sleep. 2013;36:1027-32. https://doi.org/10.5665/sleep.2802.

9. Ju Y-ES, Lucey BP, Holtzman DM. Sleep and Alzheimer disease pathology - a bidirectional relationship. Nat Rev Neurol. 2015;10:115-9. https://doi.org/10. 1038/nrneurol.2013.269.Sleep.

10. Holth JK, Fritschi SK, Wang C, Pedersen NP, Cirrito JR, Mahan TE, et al. The sleep-wake cycle regulates brain interstitial fluid tau in mice and CSF tau in humans. Science (80- ). 2019;2546:eaav2546. https://doi.org/ 10.1126/science.aav2546

11. Li S, Tian J, Bauer A, Huang R, Wen H, Li M, et al. Reduced integrity of right lateralized white matter in patients with primary insomnia: a diffusiontensor imaging study. Radiology. 2016;280:520-8. https://doi.org/10.1148/ radiol.2016152038.

12. Koo DL, Shin JH, Lim JS, Seong JK, Joo EY. Changes in subcortical shape and cognitive function in patients with chronic insomnia. Sleep Med. 2017; 35:23-6. https://doi.org/10.1016/j.sleep.2017.04.002.

13. Alperin N, Wiltshire J, Lee SH, Ramos AR, Hernandez-Cardenache R, Rundek $T$, et al. Effect of sleep quality on amnestic mild cognitive impairment vulnerable brain regions in cognitively normal elderly individuals. Sleep. 2018:1-10. https://doi.org/10.1093/sleep/zsy254.

14. Altena E, Vrenken H, Van Der Werf YD, van den Heuvel OA, Van Someren EJW. Reduced orbitofrontal and parietal gray matter in chronic insomnia: a voxel-based morphometric study. Biol Psychiatry. 2010;67:182-5. https://doi. org/10.1016/j.biopsych.2009.08.003.

15. Li M, Yan J, Li S, Wang T, Wen H, Yin Y, et al. Altered gray matter volume in primary insomnia patients: a DARTEL-VBM study. Brain Imaging Behav 2018; 0:1-9. doi:https://doi.org/10.1007/s11682-018-9844-x.

16. Winkelman JW, Plante DT, Schoerning L, Benson K, Buxton OM, O'Connor $\mathrm{SP}$, et al. Increased rostral anterior cingulate cortex volume in chronic primary insomnia. Sleep. 2013;36:991-8. https://doi.org/10.5665/sleep.2794.
17. Riemann D, Voderholzer U, Spiegelhalder K, Hornyak M, Buysse DJ, Nissen C, et al. Chronic insomnia and MRI-measured hippocampal volumes: a pilot study. Sleep. 2007;30:955-8. https://doi.org/10.1093/sleep/30.8.955.

18. Joo EY, Kim H, Suh S, Hong SB. Hippocampal substructural vulnerability to sleep disturbance and cognitive impairment in patients with chronic primary insomnia: magnetic resonance imaging morphometry. Sleep. 2014: 22-4. https://doi.org/10.5665/sleep.3836.

19. Sexton CE, Storsve AB, Walhovd KB, Johansen-Berg H, Fjell AM. Poor sleep quality is associated with increased cortical atrophy in community-dwelling adults. Neurology. 2014;83:967-73. https://doi.org/10.1212/WNL. 0000000000000774

20. Lim ASP, Yu L, Kowgier M, Schneider JA, Buchman AS, Bennett DA. Modification of the relationship of the apolipoprotein $E \varepsilon 4$ allele to the risk of Alzheimer disease and neurofibrillary tangle density by sleep. JAMA Neurol. 2013;70:1544. https://doi.org/10.1001/jamaneurol.2013.4215.

21. Hwang JY, Byun MS, Choe YM, Lee JH, Yi D, Choi J-W, et al. Moderating effect of APOE \&4 on the relationship between sleep-wake cycle and brain $\beta$-amyloid. Neurology. 2018;90:e1167-73. https://doi.org/10.1212/WNL. 0000000000005193.

22. Spiegelhalder K, Regen W, Prem M, Baglioni C, Nissen C, Feige B, et al. Reduced anterior internal capsule white matter integrity in primary insomnia. Hum Brain Mapp. 2014;35:3431-8. https://doi.org/10.1002/ hbm.22412.

23. Sexton CE, Zsoldos E, Filippini N, Griffanti L, Winkler A, Mahmood A, et al. Associations between self-reported sleep quality and white matter in community-dwelling older adults: a prospective cohort study. Hum Brain Mapp. 2017;38:5465-73. https://doi.org/10.1002/hbm.23739.

24. Molinuevo JL, Gramunt N, Gispert JD, Fauria K, Esteller M, Minguillon C, et al The ALFA project: a research platform to identify early pathophysiological features of Alzheimer's disease. Alzheimer's Dement Transl Res Clin Interv. 2016;2:82-92. https://doi.org/10.1016/j.trci.2016.02.003.

25. Kessler RC, Üstün TB. The World Mental Health (WMH) Survey Initiative version of the World Health Organization (WHO) Composite International Diagnostic Interview (CIDI). Int J Methods Psychiatr Res. 2004;13:93-121. https://doi.org/10.1002/mpr.168.

26. Haro JM, Palacín C, Vilagut G, Martínez M, Bernal M, Luque I, et al. Prevalencia de los trastornos mentales y factores asociados: resultados del estudio ESEMeD-España. Med Clin (Barc). 2006;126:445-51. https://doi.org/ $10.1157 / 13086324$

27. Gramunt N, Sánchez-Benavides G, Buschke H, Diéguez-Vide F, PeñaCasanova J, Masramon X, et al. The memory binding test: development of two alternate forms into Spanish and Catalan. J Alzheimers Dis. 2016;52: 283-93. https://doi.org/10.3233/JAD-151175.

28. Wechsler D. Wechsler Memory Scale-Fourth Edition (WMS-IV). Pearson. 2012. https://doi.org/10.1016/B978-0-444-42615-4.50011-4.

29. Goldberg D, Bridges K, Duncan-Jones P, Grayson D. Detecting anxiety and depression in general medical settings. BMJ. 1988;297:897-9. https://doi.org/ 10.1136/bmj.297.6653.897.

30. Ashburner J. A fast diffeomorphic image registration algorithm. Neuroimage. 2007;38:95-113. https://doi.org/10.1016/j.neuroimage.2007.07.007.

31. Manjón JV, Coupé P, Concha L, Buades A, Collins DL, Robles M. Diffusion weighted image denoising using overcomplete local PCA. PLoS One. 2013; 8:e73021. https://doi.org/10.1371/journal.pone.0073021.

32. Smith SM, Jenkinson M, Johansen-Berg H, Rueckert D, Nichols TE, Mackay CE, et al. Tract-based spatial statistics: Voxelwise analysis of multi-subject diffusion data. Neuroimage. 2006;31:1487-505. https://doi.org/10.1016/j. neuroimage.2006.02.024.

33. Mori S, Oishi K, Jiang H, Jiang L, Li X, Akhter K, et al. Stereotaxic white matter atlas based on diffusion tensor imaging in an ICBM template. Neuroimage. 2008;40:570-82. https://doi.org/10.1016/j.neuroimage.2007.12.035.

34. Kivipelto M, Helkala E, Laakso MP, Hänninen T, Hallikainen M, Alhainen K, et al. Midlife vascular risk factors and Alzheimer's disease in later life: longitudinal, population based study. BMJ. 2001;322:1447-51. https://doi. org/10.1136/bmj.322.7300.1447.

35. Norton S, Matthews FE, Barnes DE, Yaffe K, Brayne C. Potential for primary prevention of Alzheimer's disease: an analysis of population-based data. Lancet Neurol. 2014;13:788-94. https://doi.org/10.1016/S14744422(14)70136-X

36. LeBlanc M, Mérette C, Savard J, Ivers H, Baillargeon L, Morin CM. Incidence and risk factors of insomnia in a population-based sample. Sleep. 2009;32: 1027-37. https://doi.org/10.1093/sleep/32.8.1027. 
37. Caselli RJ, Dueck AC, Osborne D, Sabbagh MN, Connor DJ, Ahern GL, et al Longitudinal modeling of age-related memory decline and the APOE \&4 effect. N Engl J Med. 2009;361:255-63. https://doi.org/10.1056/ NEJMoa0809437.

38. Cacciaglia R, Molinuevo JL, Falcón C, Brugulat-Serrat A, Sánchez-Benavides G, Gramunt N, et al. Effects of APOE - $\varepsilon 4$ allele load on brain morphology in a cohort of middle-aged healthy individuals with enriched genetic risk for Alzheimer's disease. Alzheimers Dement. 2018:1-11. https:/doi.org/10.1016/ j.jalz.2018.01.016

39. Operto G, Cacciaglia R, Grau-Rivera O, Falcon C, Brugulat-Serrat A, Ródenas $P$, et al. White matter microstructure is altered in cognitively normal middleaged APOE- $\varepsilon 4$ homozygotes. Alzheimers Res Ther. 2018;10:48. https://doi. org/10.1186/s13195-018-0375-x.

40. Drogos LL, Gill SJ, Tyndall AV, Raneri JK, Parboosingh JS, Naef A, et al. Evidence of association between sleep quality and APOE e 4 in healthy older adults. Neurology. 2016;87:1836-42. https://doi.org/10.1212/WNL. 0000000000003255 .

41. Cappuccio FP, Taggart FM, Kandala NB, Currie A, Peile E, Stranges S, et al. Meta-analysis of short sleep duration and obesity in children and adults. Sleep. 2008;31:619-26. https://doi.org/10.1093/sleep/31.5.619.

42. Kurth F, Levitt JG, Phillips OR, Luders E, Woods RP, Mazziotta JC, et al. Relationships between gray matter, body mass index, and waist circumference in healthy adults. Hum Brain Mapp. 2013;34:1737-46. https:// doi.org/10.1002/hbm.22021.

43. Bolzenius JD, Laidlaw DH, Cabeen RP, Conturo TE, McMichael AR, Lane EM, et al. Brain structure and cognitive correlates of body mass index in healthy older adults. Behav Brain Res. 2015;278:342-7. https://doi.org/10.1016/j.bbr. 2014.10.010

44. Besteher B, Gaser C, Langbein K, Dietzek M, Sauer H, Nenadić I. Effects of subclinical depression, anxiety and somatization on brain structure in healthy subjects. J Affect Disord. 2017;215:111-7. https://doi.org/10.1016/j. jad.2017.03.039.

45. Jenkins LM, Barba A, Campbell M, Lamar M, Shankman SA, Leow AD, et al. Shared white matter alterations across emotional disorders: a voxel-based meta-analysis of fractional anisotropy. Neurolmage Clin. 2016;12:1022-34. https://doi.org/10.1016/j.nicl.2016.09.001.

46. Smith SM, Nichols TE. Threshold-free cluster enhancement: addressing problems of smoothing, threshold dependence and localisation in cluster inference. Neuroimage. 2009;44:83-98. https:/doi.org/10.1016/j.neuroimage.2008.03.061.

47. Saint Martin M, Sforza E, Barthélémy JC, Thomas-Anterion C, Roche F. Does subjective sleep affect cognitive function in healthy elderly subjects? The proof cohort. Sleep Med. 2012;13:1146-52. https://doi.org/10.1016/j.sleep. 2012.06.021.

48. Kyle SD, Sexton CE, Feige B, Luik Al, Lane J, Saxena R, et al. Sleep and cognitive performance: cross-sectional associations in the UK biobank. Sleep Med. 2017;38:85-91. https://doi.org/10.1016/j.sleep.2017.07.001.

49. Blackwell T, Yaffe K, Ancoli-Israel S, Redline S, Ensrud KE, Stefanick ML, et al. Association of sleep characteristics and cognition in older communitydwelling men: the MrOS sleep study. Sleep. 2011;34:1347-56. https://doi. org/10.5665/SLEEP.1276.

50. Fortier-Brochu É, Beaulieu-Bonneau S, Ivers H, Morin CM. Insomnia and daytime cognitive performance: a meta-analysis. Sleep Med Rev. 2012;16: 83-94. https://doi.org/10.1016/j.smrv.2011.03.008.

51. Fortier-Brochu É, Morin CM. Cognitive impairment in individuals with insomnia: clinical significance and correlates. Sleep. 2014;37:1787-98. https://doi.org/10.5665/sleep.4172.

52. Shekleton JA, Flynn-Evans EE, Miller B, Epstein $\amalg$, Kirsch D, Brogna LA, et al. Neurobehavioral performance impairment in insomnia: relationships with self-reported sleep and daytime functioning. Sleep. 2014. https://doi.org/10. 5665/sleep.3318.

53. Ling A, Lim ML, Gwee X, Ho RCM, Collinson SL, Ng TP. Insomnia and daytime neuropsychological test performance in older adults. Sleep Med. 2016;17:7-12. https://doi.org/10.1016/j.sleep.2015.07.037.

54. Cacciaglia R, Molinuevo JL, Sánchez-Benavides G, Falcón C, Gramunt N, Brugulat-Serrat $A$, et al. Episodic memory and executive functions in cognitively healthy individuals display distinct neuroanatomical correlates which are differentially modulated by aging. Hum Brain Mapp. 2018;39: 4565-79. https://doi.org/10.1002/hbm.24306.

55. Tulving E, Markowitsch HJ. Episodic and declarative memory: role of the hippocampus. Hippocampus. 1998. https://doi.org/10.1002/(SICI)10981063(1998)8:3<198::AID-HIPO2>3.0.CO;2-G
56. O'Hara R, Schroder CM, Kraemer HC, Kryla N, Cao C, Miller E, et al. Nocturnal sleep apnea/hypopnea is associated with lower memory performance in APOE 4 carriers. Neurology. 2005;65:642-4. https://doi.org/10.1212/01.wnl. 0000173055.75950.bf

57. Joo EY, Noh HJ, Kim J-S, Koo DL, Kim D, Hwang KJ, et al. Brain gray matter deficits in patients with chronic primary insomnia. Sleep. 2013;36:999-1007. https://doi.org/10.5665/sleep.2796.

58. Stoffers D, Moens S, Benjamins J, van Tol MJ, Penninx BWJH, Veltman DJ, et al. Orbitofrontal gray matter relates to early morning awakening: a neural correlate of insomnia complaints? Front Neurol 2012;1-7. doi:https://doi. org/10.3389/fneur.2012.00105.

59. Raymann RJEM, Van Someren EJW, Van Someren EJW. Diminished capability to recognize the optimal temperature for sleep initiation may contribute to poor sleep in elderly people. Sleep. 2008;31:1301-9.

60. Rolls ET, Grabenhorst F, Parris BA. Warm pleasant feelings in the brain Neuroimage. 2008;41:1504-13. https://doi.org/10.1016/j.neuroimage.2008.03.005

61. André C, Tomadesso C, de Flores $R$, Branger $P$, Rehel $S$, Mézenge F, et al. Brain and cognitive correlates of sleep fragmentation in elderly subjects with and without cognitive deficits. Alzheimer's Dement Diagnosis, Assess Dis Monit. 2019;11:142-50. https://doi.org/10.1016/j.dadm.2018.12.009.

62. Saper CB, Scammell TE, Lu J. Hypothalamic regulation of sleep and circadian rhythms. Nature. 2005;437:1257-63. https://doi.org/10.1038/nature04284.

63. Grau-Rivera O, Calvo A, Bargalló N, Monté GC, Nos C, Lladó A, et al. Quantitative magnetic resonance abnormalities in creutzfeldt-jakob disease and fatal insomnia. J Alzheimers Dis. 2016;55:431-43. https://doi.org/10. 3233/JAD-160750

64. Becker JA, Hedden T, Carmasin J, Maye J, Rentz DM, Putcha D, et al. Amyloid- $\beta$ associated cortical thinning in clinically normal elderly. Ann Neurol. 2011;69:1032-42. https://doi.org/10.1002/ana.22333.

65. Sprecher KE, Bendlin BB, Racine AM, Okonkwo OC, Christian BT, Koscik RL, et al. Amyloid burden is associated with self-reported sleep in nondemented late middle-aged adults. Neurobiol Aging. 2015:36:2568-76. https://doi.org/10.1016/J.NEUROBIOLAGING.2015.05.004.

66. Ju Y-ES, McLeland JS, Toedebusch CD, Xiong C, Fagan AM, Duntley SP, et al. Sleep quality and preclinical Alzheimer disease. JAMA Neurol. 2013;70:587. https://doi.org/10.1001/jamaneurol.2013.2334.

67. Branger $P$, Arenaza-Urquijo EM, Tomadesso C, Mézenge F, André C, de Flores $\mathrm{R}$, et al. Relationships between sleep quality and brain volume, metabolism, and amyloid deposition in late adulthood. Neurobiol Aging. 2016:41:107-14. https://doi.org/10.1016/j.neurobiolaging.2016.02.009.

68. Fortea J, Sala-Llonch R, Bartrés-Faz D, Bosch B, Lladó A, Bargalló N, et al. Increased cortical thickness and caudate volume precede atrophy in psen1 mutation carriers. J Alzheimers Dis. 2010;22:909-22. https://doi.org/10.3233/ JAD-2010-100678.

69. Fortea J, Vilaplana E, Alcolea D, Carmona-Iragui M, Sánchez-Saudinos MB, Sala I, et al. Cerebrospinal fluid $\beta$-amyloid and phospho-tau biomarker interactions affecting brain structure in preclinical Alzheimer disease. Ann Neurol. 2014;76:223-30. https://doi.org/10.1002/ana.24186.

70. Montal V, Vilaplana E, Alcolea D, Pegueroles J, Pasternak O, González-Ortiz S, et al. Cortical microstructural changes along the Alzheimer's disease continuum. Alzheimers Dement. 2017:1-12. https://doi.org/10.1016/j.jalz. 2017.09.013

71. Kivipelto M, Rovio S, Ngandu T, Kåreholt I, Eskelinen M, Winblad B, et al. Apolipoprotein E $\varepsilon 4$ magnifies lifestyle risks for dementia: a populationbased study. J Cell Mol Med. 2008;12:2762-71. https://doi.org/10.1111/j. 1582-4934.2008.00296.X

72. Roh JH, Huang Y, Bero AW, Kasten T, Stewart FR, Bateman RJ, et al. Disruption of the sleep-wake cycle and diurnal fluctuation of $\beta$-amyloid in mice with Alzheimer's disease pathology. Sci Transl Med. 2012;4:150ra122. https://doi.org/10.1126/scitranslmed.3004291.

73. Casagrande $M$, Bertini M. Night-time right hemisphere superiority and daytime left hemisphere superiority: a repatterning of laterality across wakesleep-wake states. Biol Psychol. 2008;77:337-42. https://doi.org/10.1016/j. biopsycho.2007.11.007.

74. Park DH, Shin CJ. Asymmetrical electroencephalographic change of human brain during sleep onset period. Psychiatry Investig. 2017;14:839-43. https:// doi.org/10.4306/pi.2017.14.6.839.

75. Alexander AL, Lee JE, Lazar M, Field AS. Diffusion tensor imaging of the brain Neurotherapeutics. 2007;4:316-29. https://doi.org/10.1016/j.nurt.2007.05.011.

76. Irwin MR, Olmstead R, Carroll JE. Sleep disturbance, sleep duration, and inflammation: a systematic review and meta-analysis of cohort studies and 
experimental sleep deprivation. Biol Psychiatry. 2016;80:40-52. https://doi. org/10.1016/j.biopsych.2015.05.014.

77. Lananna BV, Nadarajah CJ, Izumo M, Cedeño MR, Xiong DD, Dimitry J, et al. Cell-autonomous regulation of astrocyte activation by the circadian clock protein BMAL1. Cell Rep. 2018;25:1-9.e5. https://doi.org/10.1016/j.celrep. 2018.09.015.

78. Zhu B, Dong Y, Xu Z, Gompf HS, Ward SAP, Xue Z, et al. Sleep disturbance induces neuroinflammation and impairment of learning and memory. Neurobiol Dis. 2012;48:348-55. https://doi.org/10.1016/j.nbd.2012.06.022.

79. Vacas S, Degos V, Maze M. Fragmented sleep enhances postoperative neuroinflammation but not cognitive dysfunction. Anesth Analg. 2017;124 270-6. https://doi.org/10.1213/ANE.0000000000001675.

80. Wolf D, Fischer FU, Scheurich A, Fellgiebel A. Non-linear association between cerebral amyloid deposition and white matter microstructure in cognitively healthy older adults. J Alzheimers Dis. 2015;47:117-27. https:// doi.org/10.3233/JAD-150049.

\section{Publisher's Note}

Springer Nature remains neutral with regard to jurisdictional claims in published maps and institutional affiliations.

Ready to submit your research? Choose BMC and benefit from:

- fast, convenient online submission

- thorough peer review by experienced researchers in your field

- rapid publication on acceptance

- support for research data, including large and complex data types

- gold Open Access which fosters wider collaboration and increased citations

- maximum visibility for your research: over $100 \mathrm{M}$ website views per year

At BMC, research is always in progress.

Learn more biomedcentral.com/submissions 